\title{
Effects of High-intensity Intermittent Training and Moderate-intensity Training on Cardiopulmonary Capacity in Canoe and Kayak Paddlers during 8 Weeks
}

\author{
Ah-Ram Kim, PT, MSc, Won-Seob Shin, PT, $\mathrm{PhD}^{1 \dagger}$
}

Department of Physical Therapy, The Graduate School of Health and Medical, Daejeon University

${ }^{1}$ Department of Physical Therapy, College of Natural Science, Daejeon University

Received: July 11, 2014 / Revised: August 13, 2014 / Accepted: August 19, 2014

(c) 2014 J Korean Soc Phys Med

\section{| Abstract |}

PURPOSE: The purpose of this study was to investigate the effects of high intensity intermittent training on cardiopulmonary capacity in canoe and kayak paddlers.

METHODS: A total of 16 canoe and kayak paddlers were participated in this study. Experimental group $(\mathrm{n}=8)$ was performed high-intensity intermittent training and control group $(n=8)$ was moderate intensity training. All subjects performed a treadmill test in order to compare the difference before and after the intervention. Finishing the test, all subjects were measured to their heart rate(HR), forced vital capacity $(\mathrm{FVC})$, forced expiratory volume in one second (FEV1) and forced expiratory ratio(FEV1/FVC). Recovery of heart rate(RHR) was calculated using the HR. HR and pulmonary flow values was measured before and during the intervention period per 2, 4, 6 and 8 weeks. To compare the differences over time between experimental group and the control group, used(time $\times$ group) two-way repeated measures ANOVA. One-way repeated ANOVA was performed to

†Corresponding Author : suby96@naver.com

This is an Open Access article distributed under the terms of the Creative Commons Attribution Non-Commercial License (http://creativecommons.org/licenses/by-nc/3.0) which permits unrestricted non-commercial use, distribution, and reproduction in any medium, provided the original work is properly cited. determine where differences over time within-group.

RESULTS: One-way repeated ANOVA revealed a significant difference in the experimental and control group. In experimental group, \%RHR3min and FEV1 were significantly increased after 4 weeks $(\mathrm{p}<.05)$. Also, \%RHR1min, FVC and FEV1/FVC were significantly increased after 6 weeks(p<.05). In control group, \%RHR1min, \%RHR3min, FVC, FEV1 and FEV1/FVC were significantly increased after 6 weeks $(\mathrm{p}<.05)$.

CONCLUSION: Not only moderate training but also high-intensity intermittent training contributes to cardiopulmonary capacity in canoe and kayak paddlers. Although highintensity intermittent training is very short time, the training has high degree of efficiency. Therefore, developed this training in the future, it will be better to improve the cardiopulmonary capacity for athletes and healthy people.

Key Words: Canoe and kayak paddlers, High-intensity intermittent training, Recovery of heart rate, Pulmonary flow values

\section{Introduction}

Canoe and kayak paddlers row the distance of $200 \mathrm{~m}$, 
$500 \mathrm{~m}, 1000 \mathrm{~m}$ in the water. Canoe is selected item of Olympic game in 1936 and very famous in leisure sports. Canoe and kayak paddlers of $200 \mathrm{~m}$ competition record are less than 1 minute, $500 \mathrm{~m}$ is less than 3 minutes, $1000 \mathrm{~m}$ is 4 minutes(Jung et al, 2013). Canoe and kayak paddlers need anaerobic capacity, because they perform strong power during short time(Kim et al, 2000). Also, their cardiopulmonary endurance and power is very important (Borges et al, 2014). To improve for canoe ability, they undergo high intensity training that contain interval, resistance, endurance training(García-Pallarés et al, 2009). Especially, high intensity training was good for improving anaerobic capacity compared to moderate intensity training (Tabata et al, 1996).

Generally, Heart rate(HR) and pulmonary flow values are analyzed to compare the athlete's cardiopulmonary ability. Previous researchers measured heart rate(Danieli et al, 2014; Henríquez Olguín et al, 2013), forced vital capacity(FVC) and forced expiratory volume in one second (FEV1)(Doherty and Dimitriou, 1997), lung volume (Myrianthefs and Baltopoulos, 2013) to investigate the recovery after exercise.

Moderate intensity training and high intensity training apply to improve athlete's cardiopulmonary capacity and athletic performance. Moderate intensity training commonly uses improving cardiopulmonary endurance (Esteve-Lanao et al, 2007). Recently, Many researchers studied high intensity training for wrestlers(Etxebarria et al, 2013), swimmers(Henríquez Olguín et al, 2013), soccer player (Mohr et al, 2014), triathlete(Ramirez-Campillo et al, 2014) and significantly improved cardiopulmonary capacity. Especially, high intensity intermittent training during 4 minutes was very effective(Tabata et al, 1996). This training was same effect on moderate training during 1 hours and improved on cardiopulmonary capacity. However, Tabata ea al(1996) study subject was about healthy adults. So, we tried this training to target for canoe and kayak paddlers.

Therefore, the purpose of this study was to investigate the effects of high intensity intermittent training on cardiopulmonary capacity in canoe and kayak paddlers.

\section{Methods}

\section{Methods}

A total of 16 canoe and kayak paddlers were participated in this study. They were exercising more than five years and agreed for the study, randomly allocated experimental and control group. The subjects' genernal characteristics were as follow (Table 1). All participants were informed about the tests and the use of the results, and they formally consented to the inclusion in the study. The study was approved by the Daejeon university institutional review board(IRB), 1040647-201403-HR-011-03.

Table 1. General characteristics of participants

\begin{tabular}{lccc}
\hline & $\begin{array}{c}\text { Experimental group Control group } \\
(\mathrm{n}=8)\end{array}$ & $\mathrm{X}^{2} / \mathrm{t}$ \\
& & & \\
\hline Sex & 6 & 7 & \\
$\quad$ Male & 2 & 1 & 0.41 \\
$\quad$ Female & & & \\
Sports & 3 & 5 & 0.00 \\
$\quad$ Canoe & 5 & 5 & \\
$\quad$ Kayak & $21.75 \pm 1.04$ & $21.88 \pm 0.99$ & -0.25 \\
Age (year) & $74.00 \pm 11.84$ & $79.63 \pm 9.50$ & -1.05 \\
Weight (kg) & $172.00 \pm 6.48$ & $176.25 \pm 6.63$ & -1.30 \\
Height (cm) & $8.50 \pm 0.93$ & $8.13 \pm 0.99$ & 0.78 \\
Duration (month) & & & \\
\hline
\end{tabular}

\section{Training intervention}

Experimental group $(n=8)$ was performed high-intensity intermittent training. This training consisted of 8 sets of 20 seconds running at an intensity of about HRmax (Karvonen and Vuorimaa, 1988) with a 10 seconds rest between each bout(Tabata et al, 1996). Total time was 4 minutes. Individual HRmax was calculated using the formula; HRmax $=205.8-(0.685 \times$ age $)($ Robergs and Landwehr, 2002). 
Control group $(\mathrm{n}=8)$ was moderate intensity training. This training was 60 minutes running at an intensity of about 70\%HRR(Karvonen and Vuorimaa, 1988). Intensity was calculated using the Karvonen's formula(Karvonen and Vuorimaa, 1988). This formula is to calculate exercise heart rate at a given percentage training intensity; \%HRR= percentage of target intensity $\times($ HRmax-HRrest $)+H R r e s t$.

All subjects'are exercised for 3 times a week for 8 weeks.

\section{Measurement}

All subjects performed a treadmill test in order to compare the difference before and after the intervention (Seiler et al, 2007). The treadmill test was started at $7 \mathrm{~km} / \mathrm{h}$ and elevation was kept at $5 \%$. After a $2 \mathrm{~min}$, treadmill velocity was increased by $0.75 \mathrm{~km} / \mathrm{h}$ until the subject was no longer able to sustain oneself. Finishing the test, started the measurement immediately. Heart rate measurement was using the Polar RS400(Polar RS400, Polar electro Inc, Finland). Before the treadmill test, all subjects were measured to their HRrest., The heart rate was recorded at treadmill test termination(HRpeak), at the $1 \min (\mathrm{HR} 1)$ and at the $3 \min (\mathrm{HR} 3)$. Recovery of heart rate(RHR) were then calculated: (HRpeak-HR1,3)/HRpeak $\times 100$ (Danieli et al, 2014).

Pulmonary flow values was measured using spirometer (Microdirect Microplus Spirometer, Medical Device Depot, England). Measurements included forced vital capacity (FVC) and forced expiratory volume in one second(FEV1). The forced expiratory ratio(\%) was also calculated (FEV1/FVC) $\times 100$ (Doherty and Dimitriou, 1997).

HR and pulmonary flow values was measured before and during the intervention period per 2, 4, 6 and 8 weeks.

\section{Statistical Analyses}

All data were analyzed using SPSS ver.18.0 software. Shapiro-Wilk's test was performed to check the normality of samples. An independent t-test was used to analyze differences between the general characteristics. To compare the differences over time between experimental group and the control group, used(time $\times$ group) two-way repeated measures ANOVA. One-way repeated ANOVA was performed to determine where differences over time withingroup. Bonferroni post-hoc analysis was performed to determine significant differences. Statistical significance was set at $\mathrm{p}=.05$.

\section{Results}

\section{Recovery of heart rate(RHR)}

A two-way repeated measures ANOVA revealed no significant difference in group $(\mathrm{F}=3.695, \mathrm{p}>.05)$ and time $\times$ group interaction effect $(\mathrm{F}=0.311, \mathrm{p}>.05)$ in \%RHR $1 \mathrm{~min}$. However, effect of time was significantly different in \%RHR1min $(\mathrm{F}=28.855, \mathrm{p}<.01)$. One-way repeated ANOVA revealed a significant difference in the experimental $(\mathrm{F}=$ 157.774, $\mathrm{p}<.01)$ and control group( $\mathrm{F}=28.288, \mathrm{p}<.01)$. Both groups significantly increased after 6 weeks; however, the control group increased slightly more than experimental group in \%RHR1min.

A two-way repeated measures ANOVA revealed no significant difference in group $(\mathrm{F}=4.148, \mathrm{p}>.05)$ and time $\times$ group interaction effect $(\mathrm{F}=1.470, \mathrm{p}>.05)$ in \%RHR3min. However, effect of time was significantly different in \%RHR3min $(\mathrm{F}=63.563, \mathrm{p}<.01)$. One-way repeated ANOVA revealed a significant difference in the experimental $(\mathrm{F}=$ 48.514, $\mathrm{p}<.01)$ and control group $(\mathrm{F}=27.471, \mathrm{p}<.01)$. Both groups significantly increased, but the experimental group significantly increased 4 weeks and slightly more than control group in \%RHR3min(Table 2).

\section{Pulmonary flow values}

A two-way repeated measures ANOVA revealed no significant difference in $\operatorname{group}(\mathrm{F}=0.001, \mathrm{p}>.05)$ and time $\times$ group interaction effect $(\mathrm{F}=0.109, \mathrm{p}>.05)$ in $\mathrm{FVC}$. However, effect of time was significantly different in FVC $(\mathrm{F}=41.364$, 
$\mathrm{p}<.01)$. One-way repeated ANOVA revealed a significant difference in the experimental $(\mathrm{F}=11.397, \mathrm{p}<.05)$ and control group $(\mathrm{F}=94.891, \mathrm{p}<.01)$. Both groups significantly increased after 6 weeks; however, the control group increased slightly more than experimental group in FVC.

A two-way repeated measures ANOVA revealed no significant difference in $\operatorname{group}(\mathrm{F}=0.005, \mathrm{p}>.05)$ and time $\times$ group interaction $\operatorname{effect}(\mathrm{F}=0.642, \mathrm{p}>.05)$ in $\mathrm{FEV} 1$.

However, effect of time was significantly different in FEV1(F=91.924, $\mathrm{p}<.01)$. One-way repeated ANOVA revealed a significant difference in the experimental $(\mathrm{F}=$ 126.633, $\mathrm{p}<.01)$ and control group $(\mathrm{F}=83.181, \mathrm{p}<.01)$. Both groups significantly increased; The experimental group significantly increased after 4 weeks and control group significantly increased after 6 weeks in FEV1.

A two-way repeated measures ANOVA revealed no significant difference in $\operatorname{group}(\mathrm{F}=0.157, \mathrm{p}>.05)$ and time $\times$ group interaction effect $(\mathrm{F}=0.352, \mathrm{p}>.05)$ in $\mathrm{FEV} 1 / \mathrm{FVC}$. However, effect of time was significantly different in FEV1/FVC(F=19.160, $\mathrm{p}<.01)$. One-way repeated ANOVA revealed a significant difference in the experimental $(\mathrm{F}=$ 26.384, $\mathrm{p}<.01)$ and control group $(\mathrm{F}=20.640, \mathrm{p}<.01)$. Both groups significantly increased after 6 weeks; however, the control group increased slightly more than experimental group in FEV1/FVC (Table 3).

Table 2. Comparisons of heart rate recovery after treadmill test

\begin{tabular}{|c|c|c|c|c|}
\hline & Time & Experimental Group $(n=8)$ & Control Group $(n=8)$ & $\mathrm{F}$ \\
\hline \multirow{6}{*}{$\% \mathrm{RHR}_{1 \min }$} & Pre & $19.85 \pm 0.92$ & $20.76 \pm 1.49$ & time \\
\hline & 2 week & $20.00 \pm 0.81$ & $20.79 \pm 1.10$ & $28.86^{*}$ \\
\hline & 4 week & $20.29 \pm 1.30$ & $21.28 \pm 1.06$ & group \\
\hline & 6 week & $22.50 \pm 0.74^{\ddagger}$ & $23.02 \pm 0.78^{+}$ & 3.70 \\
\hline & 8 week & $23.39 \pm 0.69^{\ddagger}$ & $24.04 \pm 1.19^{\dagger}$ & time $\times$ group \\
\hline & $\mathrm{F}$ & $157.77^{\ddagger}$ & $22.29^{\ddagger}$ & 0.31 \\
\hline \multirow{6}{*}{$\% \mathrm{RHR}_{3 \min }$} & Pre & $44.96 \pm 1.15$ & $43.70 \pm 1.70$ & time \\
\hline & 2 week & $45.48 \pm 0.66$ & $44.24 \pm 1.51$ & $63.56^{*}$ \\
\hline & 4 week & $46.59 \pm 0.89^{\dagger}$ & $45.52 \pm 1.31$ & group \\
\hline & 6 week & $47.65 \pm 0.68^{\ddagger}$ & $47.05 \pm 1.10^{\dagger}$ & 4.15 \\
\hline & 8 week & $48.25 \pm 0.79^{\ddagger}$ & $48.15 \pm 0.77^{\ddagger}$ & time $\times$ group \\
\hline & $\mathrm{F}$ & $48.51^{\neq}$ & $27.47^{\ddagger}$ & 1.47 \\
\hline
\end{tabular}

${ }^{*} \mathrm{p}<.01$

${ }^{+}$significant difference from pre-test within group $\mathrm{p}<.05$

* significant difference from pre-test within group $\mathrm{p}<.01$

$\% \mathrm{RHR}_{1 \text { min }}$ recovery of heart rate during 1 minute after treadmill test

$\%_{\mathrm{RHR}}{ }_{3 \min }$ recovery of heart rate during 3 minute after treadmill test 
Table 3. Comparisons of pulmonary flow values after treadmill test

\begin{tabular}{|c|c|c|c|c|}
\hline & Time & Experimental Group $(\mathrm{n}=8)$ & Control Group $(\mathrm{n}=8)$ & $\mathrm{F}$ \\
\hline \multirow{6}{*}{ FVC } & Pre & $4.28 \pm 0.88$ & $4.28 \pm 0.88$ & time \\
\hline & 2 week & $4.29 \pm 0.89$ & $4.30 \pm 0.88$ & $41.36^{*}$ \\
\hline & 4 week & $4.32 \pm 0.89$ & $4.33 \pm 0.89$ & group \\
\hline & 6 week & $4.39 \pm 0.93^{\dagger}$ & $4.42 \pm 0.95^{\dagger}$ & 0.00 \\
\hline & 8 week & $4.47 \pm 0.92^{\ddagger}$ & $4.49 \pm 0.94^{\ddagger}$ & time $\times$ group \\
\hline & $\mathrm{F}$ & $11.40^{\dagger}$ & $94.89^{\ddagger}$ & 0.11 \\
\hline \multirow{6}{*}{ FEV1 } & Pre & $3.47 \pm 0.72$ & $3.49 \pm 0.71$ & time \\
\hline & 2 week & $3.49 \pm 0.73$ & $3.51 \pm 0.72$ & $91.92^{*}$ \\
\hline & 4 week & $3.54 \pm 0.72^{\ddagger}$ & $3.55 \pm 0.72$ & group \\
\hline & 6 week & $3.63 \pm 0.75^{\ddagger}$ & $3.68 \pm 0.76^{\dagger}$ & 0.01 \\
\hline & 8 week & $3.71 \pm 0.74^{\ddagger}$ & $3.75 \pm 0.75^{\dagger}$ & time $\times$ group \\
\hline & $\mathrm{F}$ & $126.63^{\ddagger}$ & $83.18^{\ddagger}$ & 0.64 \\
\hline \multirow{6}{*}{ FEV1/FVC } & Pre & $81.21 \pm 1.67$ & $81.48 \pm 1.50$ & time \\
\hline & 2 week & $81.36 \pm 1.48$ & $81.51 \pm 1.58$ & $19.16^{*}$ \\
\hline & 4 week & $81.96 \pm 1.71$ & $82.03 \pm 1.64$ & group \\
\hline & 6 week & $82.82 \pm 1.98^{\ddagger}$ & $83.29 \pm 1.98^{\ddagger}$ & 0.16 \\
\hline & 8 week & $83.08 \pm 1.75^{\ddagger}$ & $83.75 \pm 1.73^{\ddagger}$ & time $\times$ group \\
\hline & $\mathrm{F}$ & $26.38^{\ddagger}$ & $20.64^{\ddagger}$ & 0.35 \\
\hline
\end{tabular}

* $\mathrm{p}<.01$

${ }^{+}$significant difference from pre-test within group $\mathrm{p}<.05$

${ }^{\ddagger}$ significant difference from pre-test within group $\mathrm{p}<.01$

FVC forced vital capacity

FEV1 forced expiratory volume in one second

FEV1/FVC forced expiratory ratio(\%)

\section{Discussion}

In this study, we examined the RHR and lung function after high intensity intermittent training in canoe and kayak paddlers. We found that RHR and lung function were significantly higher in both groups (high intensity intermittent training and moderate training). The major finding of this study was that high intensity intermittent training was same effect on moderate training during 1 hour.

The $\%$ RHR 1,3 min was significantly different between pre and post both groups. Our study shows that experimental group's \%RHR1min before exercise was $19.85 \pm 0.92$ beats/min; after exercise( 8 weeks) was $23.39 \pm$
0.69 beats/min. control group's \%RHR1min before exercise was $20.76 \pm 1.49$ beats/min; after exercise( 8 weeks) was $24.04 \pm 1.19$ beats $/ \mathrm{min}$. Similarly, Peinado et al. showed his study that \%RHR1min after high intensity training was 24.8 \pm 8.4 (Peinado et al, 2014). Also, Our study shows that experimental group's \%RHR3min before exercise was $44.96 \pm 1.15$ beats/min; after exercise( 8 weeks) was $48.25 \pm$ 0.79 beats/min. control group's \%RHR3min before exercise was $43.70 \pm 1.70$ beats/min; after exercise( 8 weeks) was $48.15 \pm 0.77$ beats/min. In this study both group's \%RHR1, $3 \mathrm{~min}$ was significantly increased.

Our study shows the initial rapid decrease in HR after exercise. It is predominantly influenced by parasympathetic system(Kannankeril et al, 2004). Also, RHR could be 
considered training markers(Buchheit et al, 2008). Several researchers used RHR for the marker of endurance training(Buchheit et al, 2010), training status(Ostojic et al, 2010), and training load(Lamberts et al, 2010). Increased RHR means that high-intensity exercise would be improving the ability of heart rate recovery.

The results of our study show that both experimental and control groups are significant differences in FVC, FEV1 and FEV1/FVC. In experimental group FEV1 significantly increased after 4 weeks, FVC and FEV1/FVC significantly increased after 6 weeks. Control group significantly increased after 6 weeks in FVC, FEV1 and FEV1/FVC. Pulmonary flow values is one of the methods to represents respiration resistance, airways and lung function (Ferdowsi et al, 2011). Increased Pulmonary flow values was indicated improvement in respiratory muscle power and endurance(Khalili and Elkins, 2009). Rezaimanesh and Amiri-Farsani(2011) found aerobic exercise lead to increase in pulmonary functions. Another study reported FVC and FEV1 was changed according to higher intensity of exercise (Holmen et al, 2002). Ferdowsi et al. demonstrated that increase of FEV1/FVC was indicated strengthening of the expiration muscles(Ferdowsi et al, 2011).

As a result, high-intensity intermittent training affects in cardiopulmonary capacity. Tabata et al(1996) proposed that high-intensity intermittent training could be improved cardiopulmonary capacity. Lamberts et al(2010) showed a high positive correlation $(\mathrm{r}=0.67-0.81, \mathrm{p}<0.01)$ between RHR and exercise intensity. Also, Mohr et al(2014) study result was supported that high-intensity intermittent training was time-efficient training method and improved both cardiovascular health and physical performance.

Our study has some limitations. First, the number of participants was small because of elite athletes among university students. Second, we couldn't control athlete's self-exercise except the intervention. Finally we couldn't directly study connection with the athletic performance. Further study will investigate for the effects of athletic performance.

Summary, not only moderate training but also highintensity intermittent training contributes to cardiopulmonary capacity in canoe and kayak paddlers. Although highintensity intermittent training is very short time, the training has high degree of efficiency. Therefore, developed this training in the future, it will be better to improve the cardiopulmonary capacity for athletes and healthy people.

\section{Conclusions}

This study demonstrated effects of high intensity intermittent training on cardiopulmonary capacity during 8 weeks in canoe and kayak paddlers. These study results suggest that high intensity intermittent training was effective for recovery of heart rate (RHR) and lung function. Therefore, high intensity intermittent training will be a time-efficient training and significant improvement in cardiopulmonary capacity.

\section{References}

Borges TO, Bullock N, Duff C et al. Methods for quantifying training in sprint kayak. J Strength Cond Res. 2014; 28(2):474-82.

Buchheit M, Chivot A, Parouty J et al. Monitoring endurance running performance using cardiac parasympathetic function. Eur J Appl Physiol. 2010;108(6):1153-67.

Buchheit M, Millet G, Parisy A et al. Supramaximal training and postexercise parasympathetic reactivation in adolescents. Med Sci Sports Exerc. 2008;40(2): 362-71.

Danieli A, Lusa L, Potočnik N et al. Resting heart rate variability and heart rate recovery after submaximal exercise. Clin Auton Res. 2014;24(2):53-61.

Doherty M, Dimitriou L. Comparison of lung volume in Greek 
swimmers, land based athletes, and sedentary controls using allometric scaling. Br J Sports Med. 1997;31(4): 337-41.

Esteve-Lanao J, Foster C, Seiler S et al. Impact of training intensity distribution on performance in endurance athletes. J Strength Cond Res. 2007;21(3):943-49.

Etxebarria N, Anson JM, Pyne DB et al. High-intensity cycle interval training improves cycling and running performance in triathletes. Eur J Sport Sci. 2013;1-9.

Ferdowsi MH, Saiiari A, Valizadeh R et al. The effect of eight week aerobic exercise on airway trachea indexes (FEV1, FVC, FEV1. FVC \& FEF25-75) and VO2max level in overweighed male students of Ahvaz Payam Noor University. Procedia Soc. Behav. Sci. 2011; 15:2848-52.

García-Pallarés J, Sánchez-Medina L, Carrasco L et al. Endurance and neuromuscular changes in world-class level kayakers during a periodized training cycle. Eur J Appl Physiol. 2009;106(4):629-38.

Henríquez Olguín C, Báez San Martín E, Von Oetinger A et al. Autonomic control of heart rate after exercise in trained wrestlers. Biol Sport. 2013;30(2):111-15.

Holmen T, Barrett-Connor E, Clausen J et al. Physical exercise, sports, and lung function in smoking versus nonsmoking adolescents. Eur Respir J. 2002;19(1): $8-15$.

Jung JH, Song YE, Kim CH et al. Effect of periodical complex training program on the body composition and ergometer record of national canoe athletes. The Korean Journal of Sport. 2013;11(3):75-84.

Kannankeril PJ, Le FK, Kadish AH et al. Parasympathetic effects on heart rate recovery after exercise. J Investig Med. 2004;52(6):394-401.

Karvonen J, Vuorimaa T. Heart rate and exercise intensity during sports activities. Sports Med. 1988;5(5):30311.

Khalili MA, Elkins MR. Aerobic exercise improves lung function in children with intellectual disability: a randomised trial. Aust J Physiother. 2009;55(3):17175.

Kim YJ, Lee JH, Chang SD et al. Study on the cardio-respiratory function and exercise intensity in canoe players. University of Dong-A. Korea. 2000

Lamberts R, Swart J, Capostagno B et al. Heart rate recovery as a guide to monitor fatigue and predict changes in performance parameters. Scand J Med Sci Sports. 2010;20(3):449-57.

Mohr M, Nordsborg NB, Lindenskov A et al. High-intensity intermittent swimming improves cardiovascular health status for women with mild hypertension. Biomed Res Int. 2014;2014:1-9

Myrianthefs P, Baltopoulos G. A higher tidal volume may be used for athletes according to measured FVC. Scientific World Journal. 2013;2013:1-6

Ostojic SM, Markovic G, Calleja-Gonzalez J et al. Ultra short-term heart rate recovery after maximal exercise in continuous versus intermittent endurance athletes. Eur J Appl Physiol. 2010;108(5):1055-59.

Peinado A, Benito P, Barriopedro M et al. Heart rate recovery in elite Spanish male athletes. J Sports Med Phys Fitness. 2014;54(3):264-70.

Ramirez-Campillo R, Andrade DC, Álvarez C et al. The Effects of interset rest on adaptation to 7 weeks of explosive training in young soccer players. J Sports Sci Med. 2014;13(2):287-96.

Rezaimanesh D, Amiri-Farsani P. The effect of a six weeks aerobic and anaerobic intermittent swimming on VO2max and some lung volumes and capacities in student athletes. Procedia Soc. Behav. Sci. 2011; 15:2054-57.

Robergs RA, Landwehr R. The surprising history of the "HRmax=220-age" equation. J Exerc Physiol. 2002; 5(2):1-10.

Seiler S, Haugen OKuffel E. Autonomic recovery after exercise in trained athletes: intensity and duration effects. Med Sci Sports. 2007;39(8):1366. 
Tabata I, Nishimura K, Kouzaki $M$ et al. Effects of moderate-intensity endurance and high-intensity intermittent training on anaerobic capacity and VO2max. Med Sci Sports. 1996;28(10):1327-30. 